\title{
MicroRNA-665 suppresses the growth and migration of ovarian cancer cells by targeting HOXA10
}

\author{
JINHUI LIU, YI JIANG, YICONG WAN, SHULIN ZHOU, SUNITA THAPA and WENJUN CHENG
}

\begin{abstract}
Department of Gynecology, The First Affiliated Hospital of Nanjing Medical University, Nanjing, Jiangsu 210029, P.R. China
\end{abstract}
Received December 22, 2017; Accepted June 7, 2018

DOI: $10.3892 / \mathrm{mmr} .2018 .9252$

\begin{abstract}
Ovarian cancer is the most lethal gynecological cancer and its metastasis leads to a poor prognosis. The present study was designed to elucidate how microRNA (miR)-665 regulates the proliferation and migration of ovarian tumor cells. Reverse transcription-polymerase chain reaction (RT-PCR) demonstrated that miR-665 expression was decreased in ovarian cancer tissues. Increased expression of miR-665 suppressed the growth and migration of ovarian cancer cells, whereas the downregulated expression of miR-665 led to the opposite results. Bioinformatics tools identified homeobox A10 (HOXA10) as a target of miR-665. Following miR-665 overexpression, HOXA10 protein expression was significantly reduced. A dual luciferase assay revealed that miR-665 bound to the 3'-untranslated region of HOXA10. Immunohistochemistry and RT-PCR revealed that the expression of HOXA10 was negatively correlated with the expression of miR-665. It was concluded that miR-665 targets HOXA10 and may act as a tumor-suppressing gene in ovarian cancer. This pathway may be involved in the development and metastasis of ovarian cancer.
\end{abstract}

\section{Introduction}

Epithelial ovarian cancer (EOC) is a major cause for malignancy-associated female mortality (1). The mortality rate is frequently increased by a delay in diagnosis and drug resistance (2). Investigating the mechanisms behind EOC initiation and progression can help us to find a therapeutic target.

\footnotetext{
Correspondence to: Dr Wenjun Cheng, Department of Gynecology, The First Affiliated Hospital of Nanjing Medical University, 300 Guangzhou Road, Nanjing, Jiangsu 210029, P.R. China E-mail: wenjunchengdoc@163.com
}

Abbreviations: EOC, epithelial ovarian cancer; miR, microRNA; PCR, polymerase chain reaction; 3'-UTRs, 3'-untranslated regions

Key words: microRNA-665, homeobox A10, ovarian cancer, proliferation, migration
MicroRNAs (miRs), non-coding RNAs with a length of 20-24 nucleotides, regulate gene expression by inhibiting translation or degrading messenger RNA (3). Increasing evidence reveals that miRs regulate cellular processes, including proliferation, differentiation and apoptosis (3-5). A number of miRs are associated with ovarian cancer, and may regulate tumor progression, function as potential prognostic markers and contribute to drug resistance (6-9). The functions of miRs in carcinogenesis have been illustrated in multiple studies. For example, miR-224, as an oncogene in EOC, improves cancer cell proliferation by downregulating KILLIN expression (10). By targeting pyruvate dehydrogenase E1 $\beta$ subunit, miR-203 promotes the proliferation and migration of EOC cells (11). Other miRs function as tumor suppressors expressed $(12,13)$. For example, by targeting cyclin dependent kinase (CDK1), miR-490-3p inhibits the proliferation, migration and invasion of EOC cells (12). miR-101 suppresses the expression of the suppressor of cytokine signaling 2 gene and inhibits the proliferation and invasion of EOC cells (13). Among them, miR-655 was the focus of the present study as it has been demonstrated to play a role in certain malignancies, including esophageal squamous cell carcinoma (14), bladder urothelial carcinoma (15) and gastric signet ring cell carcinoma (16). Currently, to the best of our knowledge, no studies have been conducted to investigate the association between miR-665 and EOC.

Homeobox A10 (HOXA10), one member of the homeobox gene family, acts as a transcription factor in embryonic development (17). The aberrant expression of HOXA10 was first observed in leukemia (18). The association between HOXA10 and EOC can be demonstrated by the downregulation and upregulation of HOXA10 in cancer cellular processes, including cell proliferation, epithelial-mesenchymal transition, apoptosis and drug resistance $(6,18-22)$. HOXA10 was demonstrated to participate in G1 phase arrest of endometrial cancer that may be caused by $\mathrm{P}^{21}$ expression (23). It was hypothesized that miR-665 can regulate HOXA10 expression, based on the data from PicTar, TargetScan and miRBase. However, the role of miR-665 in the development of EOC and its association with HOXA10 remains uninvestigated.

In the present study, the expression of miR-665 in human EOC and normal ovary tissues were compared, and the impact of miR-665 expression on cell proliferation and migration in vitro was investigated. The results of the present study suggested that miR-665 serves a suppressive role in human EOC pathogenesis. 


\section{Materials and methods}

Tissue samples and cell lines. Informed consent was obtained from each patient. The present study was approved by the Institutional Ethic Committee of Nanjing Medical University (Nanjing, China). Tissues from EOC patients were frozen immediately and stored at $-80^{\circ} \mathrm{C}$. EOC tissue specimens $(n=28)$ and normal ovarian tissue specimens $(n=15)$ were collected from patients (age range, 24-73) who underwent surgery at the Department of Gynecology at the First Affiliated Hospital of Nanjing Medical University (Nanjing, China) between December 2014 and December 2015. EOC cell lines (HO8910 and OVCAR-3) and 293T cells were purchased from American Type Culture Collection (Manassas, VA, USA). Cells were cultured in RPMI-1640 medium (Gibco; Thermo Fisher Scientific, Inc., Waltham, MA, USA) containing 10\% fetal bovine serum (FBS; Gibco; Thermo Fisher Scientific, Inc.), $100 \mathrm{U} / \mathrm{ml}$ penicillin, and $100 \mathrm{mg} / \mathrm{ml}$ (Beijing Solarbio Science and Technology Co., Ltd., Beijing, China) at $37^{\circ} \mathrm{C}$ with $5 \% \mathrm{CO}_{2}$.

Reverse transcription-quantitative polymerase chain reaction (RT-qPCR) analysis. Total RNA was extracted from ovarian tissues and ovarian cancer cell lines using TRIzol reagent (Thermo Fisher Scientific, Inc., Waltham, MA, USA) following the manufacturer's protocol. Following isolation, the integrity of RNA was determined using Agilent Bioanalyzer 2100 and RNA 6000 Nano kit (Agilent Technologies, Inc., Santa Clara, CA, USA). According to manufacturer's protocol, single-stranded complementary DNA (cDNA) was synthesized from $1 \mu \mathrm{g}$ RNA in a $20 \mu 1$ reaction volume with the High-Capacity cDNA Reverse Transcription kit (Thermo Fisher Scientific, Inc.), at $25^{\circ} \mathrm{C}$ for $10 \mathrm{~min}, 37^{\circ} \mathrm{C}$ for $120 \mathrm{~min}$ and $85^{\circ} \mathrm{C}$ for $5 \mathrm{sec}$, followed by a $4^{\circ} \mathrm{C}$ hold. Quantification of miR and mRNA was carried out using a SYBR Green PCR kit (Thermo Fisher Scientific, Inc.), and the cycle quantification $(\mathrm{Cq})$ of each gene was recorded. The relative expression of miR-665 mRNA and HOXA10 was normalized to U6, and calculated using the $2^{-\Delta \Delta C q}$ method $\left(\Delta \mathrm{Cq}=\mathrm{Cq}^{\text {target gene }}-\mathrm{Cq}^{\text {internal }}\right.$ control) (24). The qPCR was performed using the following parameters: $95^{\circ} \mathrm{C}, 10 \mathrm{~min} ; 40$ cycles, $95^{\circ} \mathrm{C}, 15 \mathrm{sec} ; 67^{\circ} \mathrm{C}$, $30 \mathrm{sec} ; 72^{\circ} \mathrm{C}, 30 \mathrm{sec}$; and $72^{\circ} \mathrm{C}, 5 \mathrm{~min}$. The primers used are illustrated in Table I.

Protein extraction and western blotting. At $48 \mathrm{~h}$ following transfection, the cells were harvested, washed twice with phosphate-buffered saline, lysed using M-PER ${ }^{\mathrm{TM}}$ Mammalian Protein Extraction reagent (Thermo Fisher Scientific, Inc., Waltham, MA, USA) with $0.01 \%$ protease and phosphatase inhibitor, and incubated on ice for $30 \mathrm{~min}$. The cell lysate was centrifuged at $4^{\circ} \mathrm{C}$ and $12,000 \mathrm{x}$ g for $15 \mathrm{~min}$. Protein concentrations were determined by a bicinchoninic acid protein assay (Beyotime Institute of Biotechnology, Haimen, China). The supernatant $(50 \mu \mathrm{g})$ of total protein was run on $10 \%$ SDS-PAGE and transferred electrophoretically to a polyvinylidene fluoride membrane (EMD Millipore, Billerica, MA, USA). Following blocking in Western Blocking Reagent (10\%; Hoffman; Roche Diagnostics, Basel, Switzerland) for $15 \mathrm{~min}$ at room temperature, the membrane was incubated overnight at $4^{\circ} \mathrm{C}$ with polyclonal rabbit anti-human HOXA10
(1:1,000; Abcam, Cambridge, MA, USA; cat. no. ab90641) and mouse anti-human $\beta$-actin (1:10,000; cat. no. ab49900; Abcam), respectively. The membranes were washed with $1 \mathrm{X}$ Tris-buffered saline containing $0.1 \%$ Tween-20 (TBST), incubated with the horseradish peroxidase (HRP)-conjugated anti-rabbit $\operatorname{IgG}$ secondary antibody (1:1,000; cat. no. 7074; Cell Signaling Technology, Inc.) at room temperature for $1 \mathrm{~h}$. Membranes were washed again with TBST three times for $10 \mathrm{~min}$ each, prior to visualization and analysis using the Odyssey IR imaging system (LI-COR Biosciences, Lincoln, NE, USA).

Bioinformatics analysis. To investigate the target genes of miR-665, TargetScan version 7.1 (http://www.targetscan.org), PicTar 5 (https://pictar.mdc-berlin.de/) and miRBase release 22 (http://www.mirbase.org/) were used to predict the potential target gene of miR-665.

Transwell migration assay. Following being placed into a 24-well plate, the migration assays of OVCAR-3 and HO8910 cells were carried out using Transwell chambers (EMD Millipore). For the migration assay, a total of $1 \times 10^{5}$ cells were resuspended in $200 \mu \mathrm{l}$ serum-free medium and placed in the top chambers. RPMI-1640 medium $(600 \mu \mathrm{l})$ containing $10 \%$ FBS was added into the bottom chambers. Cells were incubated for another $20 \mathrm{~h}$ at $37^{\circ} \mathrm{C}$ with $5 \% \mathrm{CO}_{2}$. The cells were fixed with $4 \%$ polyoxymethylene following the incubation for $20 \mathrm{~min}$ at room temperature, stained with $0.1 \%$ crystal violet for $20 \mathrm{~min}$ at room temperature and observed using a light microscope (magnification, x100; Olympus Corporation, Tokyo, Japan). The numbers of migrated cells were calculated from five randomly selected fields.

Colony formation assay. Cells were transfected with NC, miR-665, as described above. Then $24 \mathrm{~h}$ later, transfected cells were trypsinized, counted and replated at a concentration of 500 cells/well. Following another 10 days, colonies formed by the surviving cells were fixed with $3.7 \%$ methanol for $20 \mathrm{~min}$ at room temperature, stained with $0.1 \%$ crystal violet for $20 \mathrm{~min}$ at room temperature and counted. Colonies containing $\geq 50$ cells were scored. Each assay was performed in triplicate.

CCK- 8 assay. The cell proliferation reagent WST-8 (Roche Diagnostics GmbH, Mannheim, Germany) was used to measure cell growth. Cells were seeded into 96-well microtiter plates (Corning Inc., Corning, NY, USA) at a density of $1.0 \times 10^{3}$ cells/well. CCK-8 was added to each well according to the manufacturer's protocol. Following incubation at $37^{\circ} \mathrm{C}$ with $5 \% \mathrm{CO}_{2}$ for $2 \mathrm{~h}$, the absorbance of the converted dye was detected at $450 \mathrm{~nm}$ to determine the cellular viability.

Dual-luciferase reporter assay. The 3'-untranslated regions (3'-UTRs) of human HOXA10 cDNA with the potential target sites for miR-665 were synthesized and inserted at the $\mathrm{XbaI}$ site downstream of the luciferase gene in the pGL3-control (Promega Corporation, Madison, WI, USA) vector by Integrated Biotech Solutions Co., Ltd., (Shanghai, China).

At $24 \mathrm{~h}$ prior to transfection, cells were seeded in 24 -well plates $\left(1.5 \times 10^{5}\right.$ wells/well). Then, $200 \mathrm{ng}$ of pGL3-HOXA10-3'-UTR and $80 \mathrm{ng}$ of pRL-TK (Promega 
Table I. Primers used in reverse transcription-quantitative polymerase chain reaction and miR sequences.

\begin{tabular}{lll}
\hline Name & Direction & Sequence $\left(5^{\prime}-3^{\prime}\right)$ \\
\hline U6 & Forward & CTCGCTTCGGCAGCACA \\
Hsa-miR-665 mimic & Reverse & AACGCTTCACGAATTTGCGT \\
& Forward & ACCAGGAGGCUGAGGCCCCUTT \\
miR-665 mimic negative control & Reverse & AGGGGCCUCAGCCUCCUGGUTT \\
& Forward & UUCUCCGAACGUGUCACGUTT \\
Hsa-miR-665 inhibitor & Reverse & ACGUACACGUUCGGAGAATT \\
miR inhibitor negative control & & AGGGGCCUCAGCCUCCUGGU \\
& & CAGUACUUUUGUGUAGUACAA \\
& Forward & GGGTAAGCGGAATAAACT \\
\hline
\end{tabular}

miR, microRNA.

Corporation) were co-transfected with 60 pmol of miR-665 mimic or NC using Lipofectamine ${ }^{\circledR} 2000$ (Invitrogen; Thermo Fisher Scientific, Inc.) according to the manufacturer's protocol. At $24 \mathrm{~h}$ following the transfection, the Dual-luciferase assay system (Promega Corporation) was used to determine luciferase activity as previously described (6). The firefly luciferase activity in each well was normalized to that of the Renilla luciferase. Three independent experiments were performed in duplicate. The sequence of 3' UTR of human HOXA10 cDNA containing the putative target site for the miR-665; the underlined, italicized area indicates the putative target site for miR-665: 5'-TGAATCTCCAGGCGACGCGGTTTTTTC ACTTCCCGAGCGCTGGTCCCCTCCCTCTGTCTTCAG GCTCTGCCCAGGAACTCGCACCTGTGCTGGAGCCCT GTTCCTCCCTCCCACACTCGCCATCTCCTGGGCCGT TACATCTGTGCAGGGCTGGTTTGTTCTGACTTTTTG TTTCTTTGTGTTTGCTTGGTGCTGGTTTATTTGTTG TTTTCTGGGGGAAAAAGCCATATCATGCTAAAATTC TATAGAGATA-3'.

Immunohistochemistry. The tissues were fixed in $10 \%$ formalin for $24 \mathrm{~h}$ at room temperature, embedded in paraffin and $4 \mu \mathrm{m}$ thick sections were prepared. Microwave irradiation in $10 \mathrm{~mol} / \mathrm{l}$ citrate buffer $(\mathrm{pH} \mathrm{6.0)}$ was used for antigen retrieval for tissue slides incubated with a HOXA10 antibody (1:500; cat. no. ab90641; Abcam) at $4^{\circ} \mathrm{C}$ overnight, followed by incubation with a HRP-conjugated secondary antibody (1:1,000; cat. no. ab6721; Abcam) for $1 \mathrm{~h}$ at room temperature. The staining was repeated if the result was uncertain. Immunostaining of the slides was objectively evaluated by two pathologists under a light microscope (magnification, x200; Olympus Corporation, Tokyo, Japan). Discordant scores were reevaluated until consensus was reached. The level of positive HOXA10 expression in cancer cells was analyzed by HMIAS-2000 automatic medical color image analysis system (Qianping Image Technology Co., Ltd., Wuhan, China). HOXA10 staining was determined semi-quantitatively according to the staining intensity observed $(0$, no staining; 1,weak staining; 2 , moderate staining; and 3, strong staining) and the percentage of positive cells $(0$, none or $<10 ; 1,11-25$;
$2,26-50$; and $3,51-75 \% ; 4,>75 \%$ ). Scores of $0-3$ were considered to indicate negative expression, and scores of 3-12 were considered to indicate positive expression. Cells were counted in at least three randomly selected fields (magnification, x200) in the tumor areas.

Statistical analysis. All experiments were repeated three times independently. The results were summarized as the mean \pm standard error. Independent sample t-tests were performed to compare differences between two groups with SPSS 19.0 software (IBM Corp., Armonk, NY, USA). Spearman's correlation test was used to analyze the correlation between miR-655 and HOXA10 expression. $\mathrm{P}<0.05$ was considered to indicate a statistically significant difference.

\section{Results}

Expression level of HOXA10 increases in EOC tissues. Immunohistochemical staining was used to determine the level of HOXA10 expression in both normal and ovarian cancer tissues. HOXA10 expression of 15 EOC specimens and 8 normal specimens were analyzed in the present study. Immunohistochemical staining identified that the HOXA10 protein levels were significantly increased in the ovarian cancer tissues compared with the normal tissues $(\mathrm{P}<0.01$; Fig. 1$)$.

miR-665 targets the 3'-UTR of HOXA10. TargetScan7.1 (http://www.targetscan.org) was used to predict whether HOXA10 is targeted by miR-665 (Fig. 2A). In the 293T cell line, relative activity of luciferase was significantly decreased $(\mathrm{P}<0.01)$ following the co-transfection of the pGL3-HOXA10-3'-UTR vector with the miR-665 mimic, but not following the co-transfection of pGL3-HOXA10-3'-UTR vector with mimic $\mathrm{NC}$, suggesting that HOXA10 is the target gene of miR-665 (Fig. 2B). Western blotting was performed to confirm the downregulation of the HOXA10 protein following the miR-665 transfection in HO8910 and OVCAR-3 EOC cells. The protein expression level of HOXA10 significantly decreased in miR-665-transfected cells, compared with cells transfected with miR-NC $(\mathrm{P}<0.01$; Fig. $2 \mathrm{C}$ and $\mathrm{D})$. Then 
A

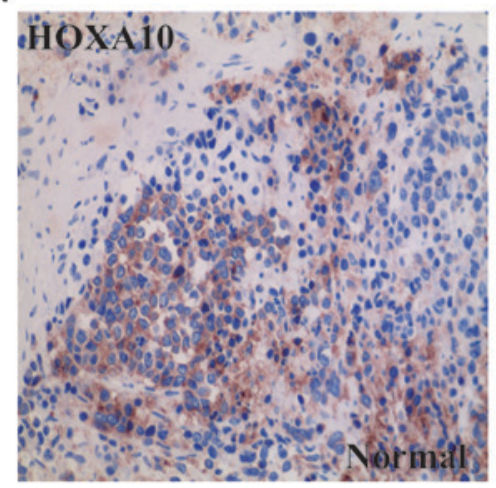

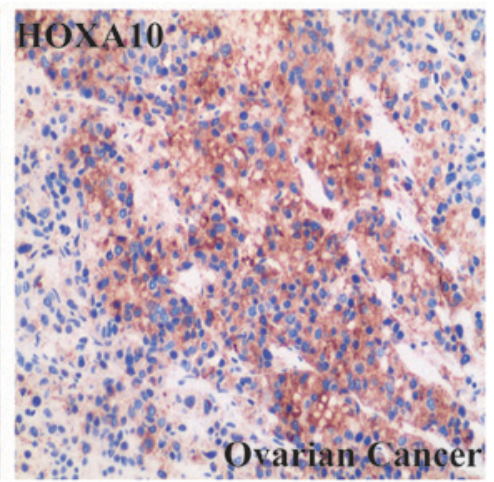

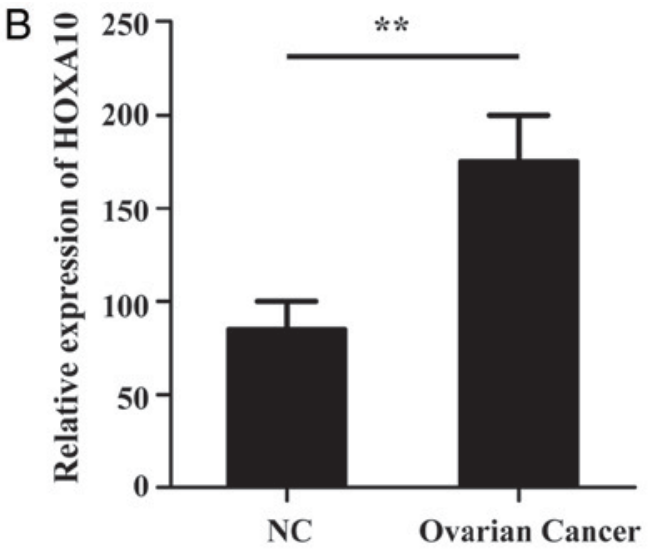

Figure 1. Overexpressed HOXA10 in ovarian cancer. (A) Immunofluorescence staining for HOXA10 in ovarian cancer tissues and normal ovary tissues. (B) Semi-quantification of HOXA10 staining. Magnification, x200. ${ }^{* *} \mathrm{P}<0.01$. HOXA10, homeobox A10; NC, negative control.

A HOXA10 3' UTR 5' ...UCCCACACUCGCCAUCUCCUGGG..
miR-665 3'

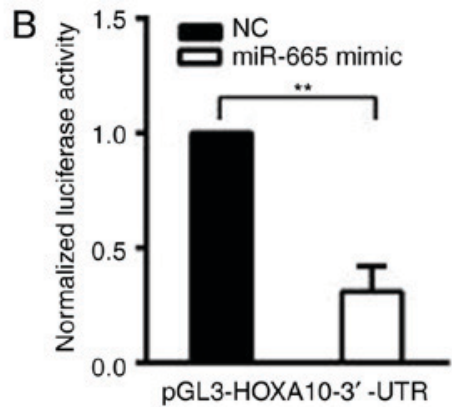

C
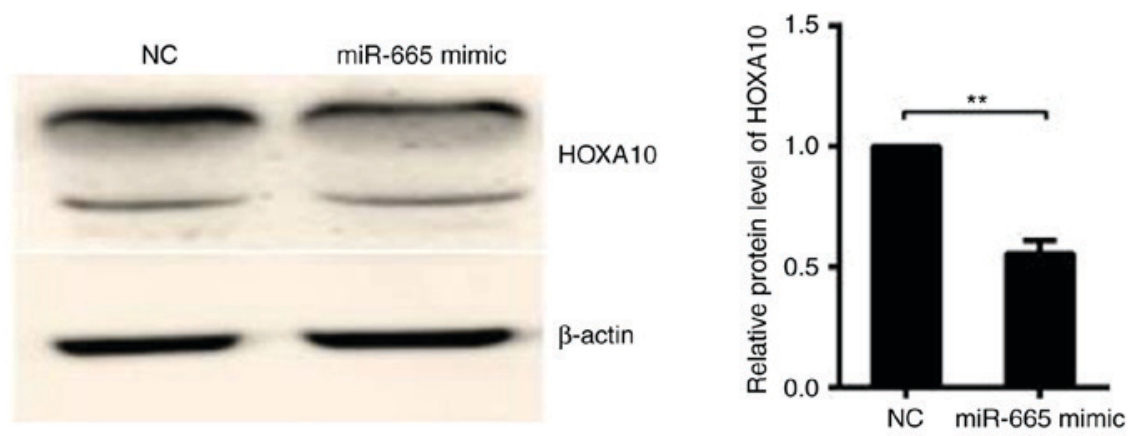

D

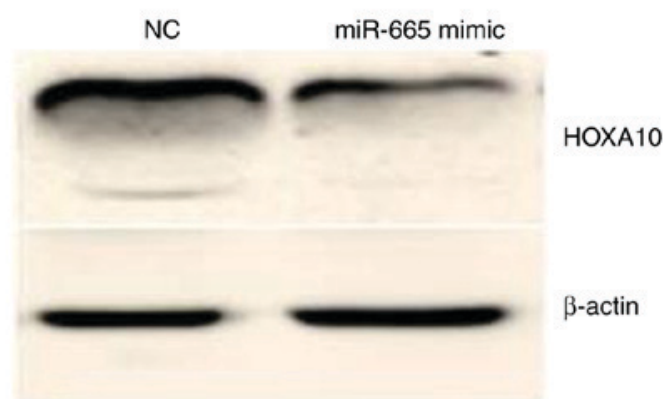

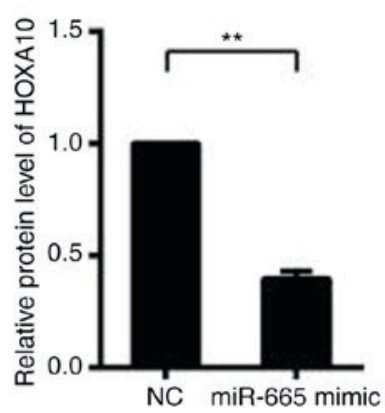

Figure 2. HOXA10 is a candidate target of miR-665. (A) Computational analysis identified that HOXA10 may be a potential target of miR-665 and the binding sequences of HOXA10 3'-UTR and miR-665 were marked. (B) Dual luciferase assay performed in 293T cells suggested that HOXA10 was the target gene of miR-665. A significant decrease in relative luciferase activity was noted when pGL3-HOXA10-3'-UTR was cotransfected with miR-665 mimic, but not with the miR mimic NC. (C) Measurement of HOXA10 expression levels by western blotting analysis. Protein was extracted from HO8910 cells transfected with the miR-665 mimic or NC mimic. The endogenous expression levels of the $\beta$-actin protein were used for normalization and the relative HOXA10 protein expression levels are illustrated. (D) Protein was extracted from OVCAR-3 cells transfected with the miR-665 mimic or mimic NC. The endogenous expression levels of the $\beta$-actin protein were used for normalization and the relative HOXA10 protein expression levels were demonstrated. All experiments were performed in triplicate. ${ }^{* *} \mathrm{P}<0.01$. HOXA10, homeobox A10; UTR, untranslated region; miR, microRNA; NC, negative control.

whether HOXA10 is the target of miR-665 was investigated. A luciferase reporter vector was constructed with the target sites of putative HOXA10 3'-UTR (luciferase gene) located in the downstream of miR-665. The luciferase reporter vector, 
miR-665 mimic and mimic NC was then transfected into 293T cells.

miR-665 is negatively associated with HOXA10. qPCR was used to determine the expression of miR-665 in $28 \mathrm{EOC}$ specimens and 15 normal specimens. Compared with normal tissues, expression level of miR-665 significantly dropped in ovarian cancer tissues, suggesting that miR-665 is downregulated in ovarian cancer tissues and may be involved in the development of ovarian cancer $(\mathrm{P}<0.01$; Fig. 3A). A significant inverse correlation $\left(\mathrm{R}^{2}=0.7496 ; \mathrm{P}<0.01\right)$ was observed between miR-665 and HOXA10 using Spearman's correlation analysis (Fig. 3B).

miR-665 suppresses cell growth in vitro. HO8910 and OVCAR-3 cells were transfected with the miR-665 mimic. Subsequently, CCK-8 assays were performed to determine the impact of miR-665 on the proliferation of ovarian cancer cells. The results identified that increased expression of miR-665 significantly suppressed the proliferation of ovarian cancer cells in both cell lines $(\mathrm{P}<0.05$; Fig. $4 \mathrm{~A}$ and $\mathrm{B})$. The colony formation capacity of HO8910 and OVCAR-3 cells transfected with miR-665 mimic was significantly inhibited compared with the miR-NC group ( $\mathrm{P}<0.05$; Fig. $4 \mathrm{C}$ and $\mathrm{D})$. These results demonstrated that miR-665 inhibits the proliferative ability of HO8910 and OVCAR-3 cells.

miR-665 suppresses the migration of ovarian cancer cells. Transwell migration assay demonstrated that miR-665-overexpressed HO8910 and OVCAR-3 cells exhibited a significantly decreased ability to migrate compared with the control cells $(\mathrm{P}<0.05$; Fig. 5).

Inhibition of miR-665 promotes the growth and migration of ovarian cancer cell lines. The colony formation rate of HO8910 and OVCAR-3 cells transfected with miR-665 inhibitor, was significantly increased, compared to cells transfected with the miR-NC inhibitor ( $\mathrm{P}<0.05$; Fig. $6 \mathrm{~A}$ and $\mathrm{B})$. The migratory abilities of miR-665-downregulated HO8910 and OVCAR-3 cells were significantly enhanced compared with the miR-NC inhibitor $(\mathrm{P}<0.05$; Fig. 6C and $\mathrm{D})$.

\section{Discussion}

Ovarian cancer is the most lethal cancer for women, with an overall survival rate of $\sim 35 \%$ (25). Although modified chemotherapy can improve the prognosis, its effectiveness has reached its limit. Consequently, novel therapies, such as targeted therapy combined with standard treatment, are being investigated in clinical trials (26). In these trials, predictive markers can be used to personalize and optimize the therapeutic strategy for ovarian cancer (27).

miRs modulate gene expression in a post-transcriptional manner either by inhibiting translation or destroying the target mRNA (28). miRs are aberrantly expressed in ovarian cancer. For example, the expression of miR-145 is significantly reduced in human ovarian cancer tissues, leading to relapse and poorer outcomes of ovarian cancer (29). miR-490-3p overexpression inhibits the proliferation, migration and invasion of tumor cells by directly targeting CDK1 (12). In addition, miR-497
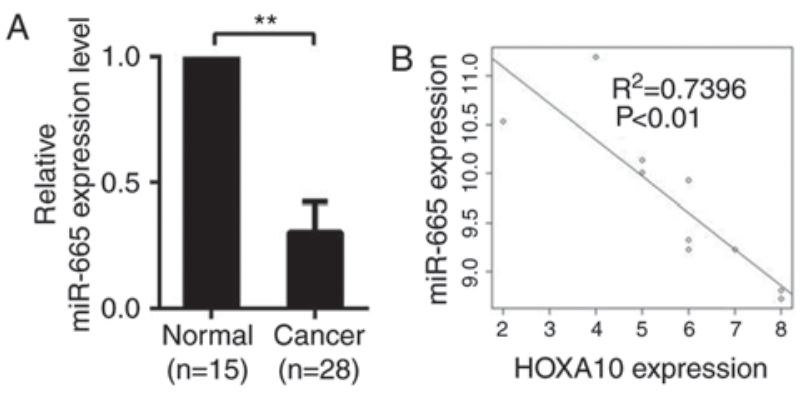

Figure 3. miR-665 is negatively associated with HOXA10. (A) The expression levels of miR-665 in ovarian cancer tissues $(n=28)$ and normal ovarian tissues $(n=15)$. Significantly lower expression of miR-665 was detected in ovarian cancer tissues compared with the normal ovarian tissues. (B) A plot of the relative expression of miR-665 vs. HOXA10 demonstrated an inverse correlation between the two parameters. The correlation index $\mathrm{R}^{2}$ was calculated using the Spearman's rank test $\left(\mathrm{R}^{2}=0.7496 ; \mathrm{P}<0.01\right)$. The $\mathrm{X}$-axis indicates the immunohistochemistry scores. The $\mathrm{y}$-axis indicates the relative expression determined by reverse transcription-quantitative polymerase chain reaction (normalized to U6). ${ }^{* *} \mathrm{P}<0.01$. miR, microRNA; HOXA10, homeobox A10.

downregulation triggers chemotherapy resistance in ovarian cancer cells (30). The level of miR-125b expression in ovarian cancer tissue is significantly lower compared with normal ovarian tissues; the increased expression of miR-125b induces cell cycle arrest and inhibits the proliferation and clonal formation of ovarian cancer cells by targeting BCL-3 (31).

In carcinogenesis, miR-665 demonstrates diverse functions (14-16) that are co-regulated by its targets (32). miR-665, located at 14q32.2, with a length of 20 amino acids, can inhibit B7-H3 expression. However, the underlying mechanism remains uninvestigated. In the present study, the analysis of RNA expression revealed that the expression of hsa-miR-665 was decreased in EOC, which is consistent with the results of a previous study on breast cancer (33). Therefore, it is hypothesized that miR-665 may function as a tumor-suppressor gene in ovarian cancer. Certain studies demonstrated that miR-665 expression was dysregulated in a number of types of cancer, including esophageal squamous cell carcinoma (14), bladder urothelial carcinoma (15) and gastric signet ring cell carcinoma (16).

HOXA10, from the homeobox gene family, functions as a transcription factor in embryonic development (17). It has been suggested that HOXA10 acts as a key factor in endometrial receptivity and embryo implantation, and is expressed in endometrial glandular epithelium and mesenchymal cells in normal humans (34). The HOXA10 expression level in the middle and late stages of secretion is increased compared with the period of endometrial proliferation and the early stage of secretion (35). As the progesterone concentration rises during implantation and embryonic circulation, the level of HOXA10 gradually reaches a peak, indicating that HOX genes regulate endometrial development and embryonic planting $(35,36)$. In addition, HOXA10 is highly expressed in endometroid, clear or mucinous cells, but not in serous epithelial ovary cancer cells $(37,38)$. Aberrant HOX gene expression has been reported in several types of cancer, including glioblastoma (39), oral cancer and gastric cancer $(21,22,40)$. Increased expression of HOXA10 promotes the proliferation, migration and invasion of clear cell adenocarcinoma of the ovary, reducing the survival 
A

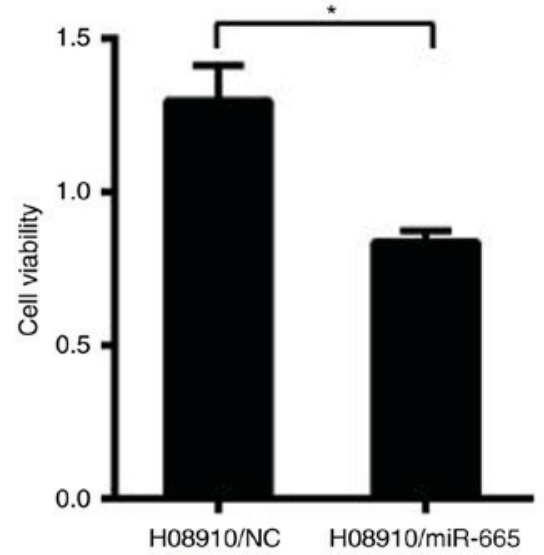

C

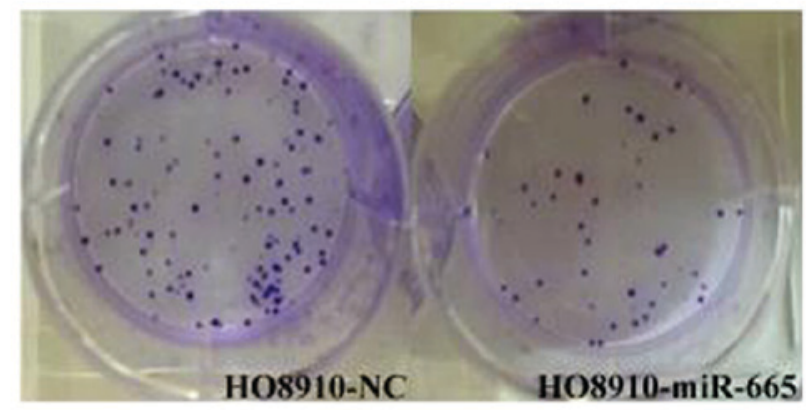

D

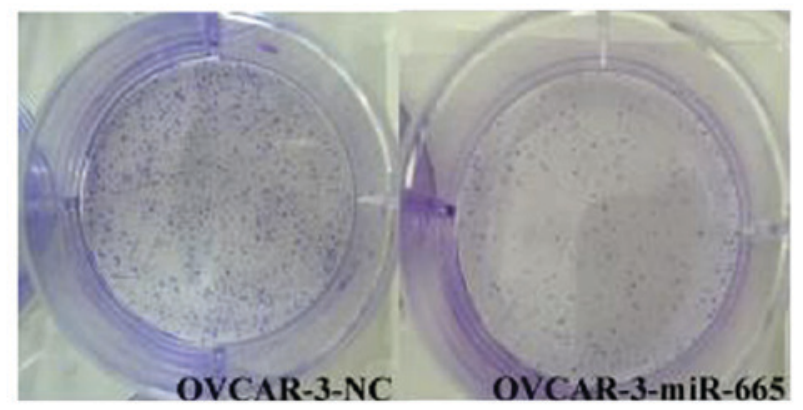

B

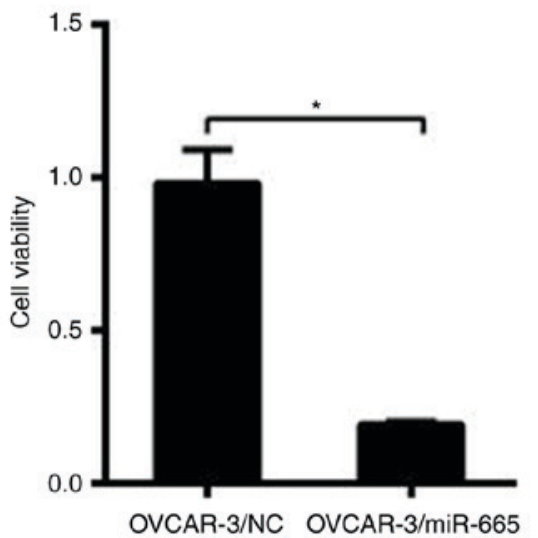

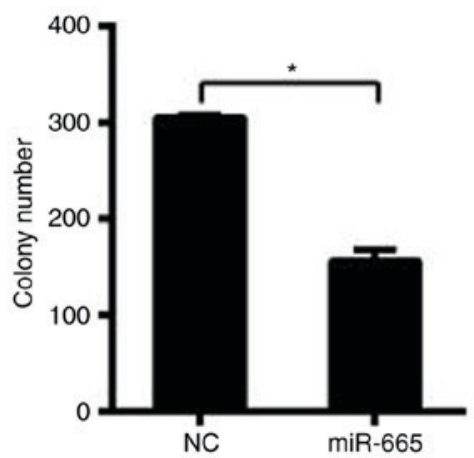

Figure 4. miR-665 significantly decreases the proliferation of ovarian cancer cells. Cell viability was detected using CCK-8 in (A) H08910 and (B) OVCAR-3 cells. HO8910 and OVCAR-3 cells were transfected with the miR-665 mimic or mimic NC, then the CCK-8 assay was used to determine the relative cell growth activity at $1 \mathrm{~h}$ post-transfection. Effect of miR-665 on cell proliferation evaluated by a colony formation assay in (C) H08910 and (D) OVCAR-3 cells. HO8910 and OVCAR-3 cells transfected with miR-665 mimic or mimic NC were seeded into 6-well plates. On day 10 after seeding, the number of colonies was counted. ${ }^{\mathrm{P}}<0.05$. miR, microRNA; NC, negative control.

of patients (41). The present study identified that miR-665 was downregulated and negatively correlated with the expression of HOXA10 in ovarian tumor tissues, indicating that miR-665 may be a tumor suppressor gene in the development of ovarian cancer and a potential therapeutic target for ovarian cancer.

In the present study, the RT-qPCR results demonstrated that miR-665 was downregulated in ovarian cancer tissues compared with normal tissues. Immunohistochemistry revealed that HOXA10 was overexpressed in ovarian cancer tissues and this expression was negatively correlated with the expression of miR-665. It was also demonstrated that miR-665 suppressed the proliferation and migration of cell lines, whereas the downregulation of miR-665 led to the opposite effect, as it bound to the 3'-UTR of HOXA10, and downregulated HOX10 by reducing HOXA10 protein levels. Further studies are needed to elucidate the mechanism of HOXA10 silencing.
The present study investigated the expression and biological function of miR-665 in ovarian cancer. miR-665 downregulated the expression of HOXA10 and weakened the ability of ovarian cancer cells to proliferate and migrate. miR-665, through targeting HOXA10, serves as a suppressor gene in ovarian cancer. Therefore, therapeutic miR that mimics miR-665 could possibly be developed to treat ovarian cancer.

\section{Acknowledgements}

Not applicable.

\section{Funding}

The present study was supported by the National Nature Science Foundation of China (grant nos. 81472442 
A

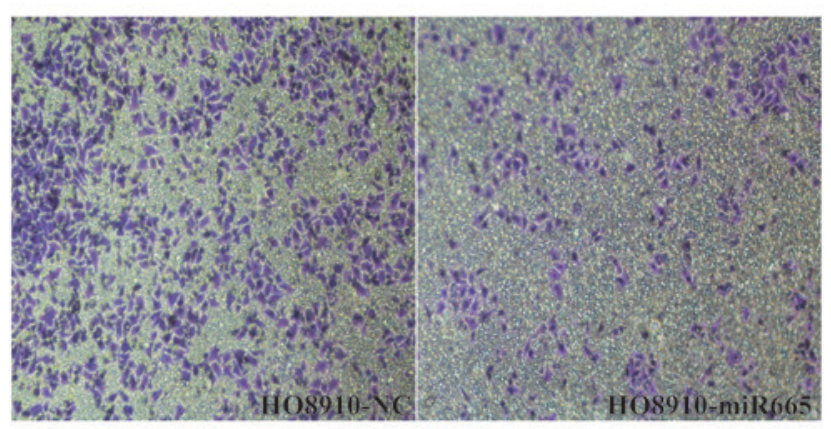

B

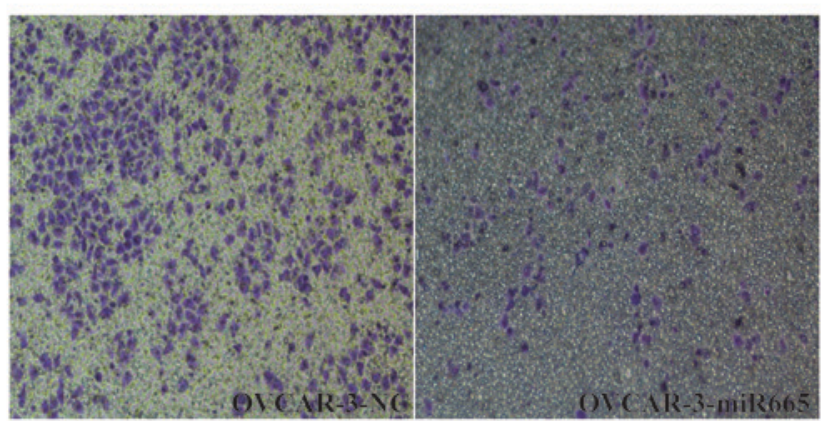

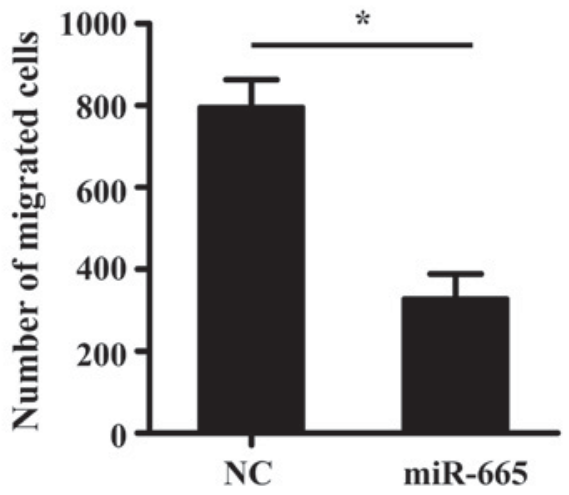

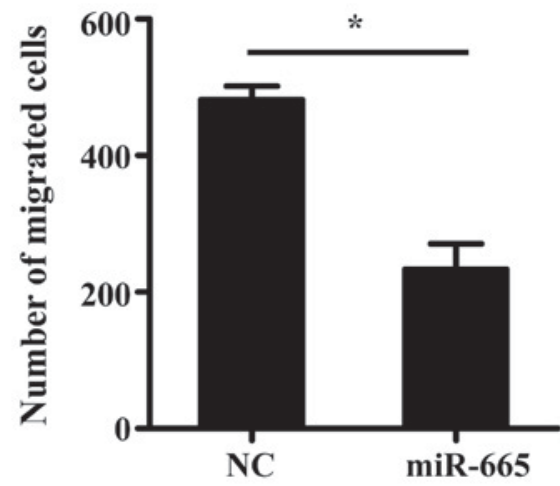

Figure 5. miR-665 reduces cell migration in ovarian cancer cells. (A) HO8910 and (B) OVCAR-3 cells were transfected with miR-665 mimic or mimic NC for $48 \mathrm{~h}$. Then, the Transwell chambers were stained with $0.1 \%$ crystal violet and counted. The number of migrating cells of ovarian cancer cells transfected with miR-665 decreased more compared with the mimic NC group. Magnification, x100. ${ }^{*} \mathrm{P}<0.05$. miR, microRNA; NC, negative control.

A

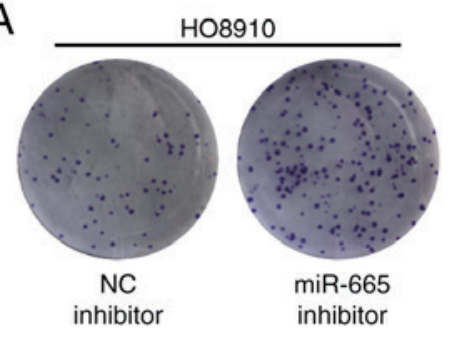

$\mathrm{C}$

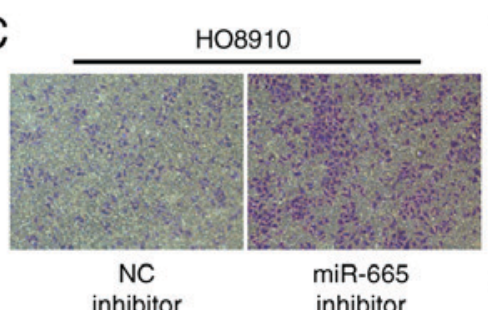

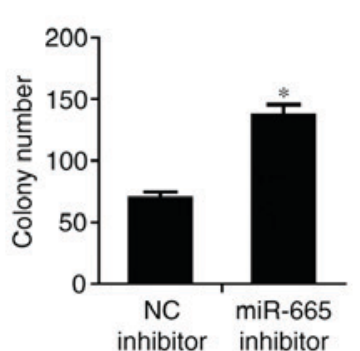

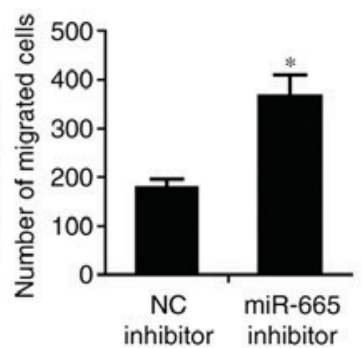

B

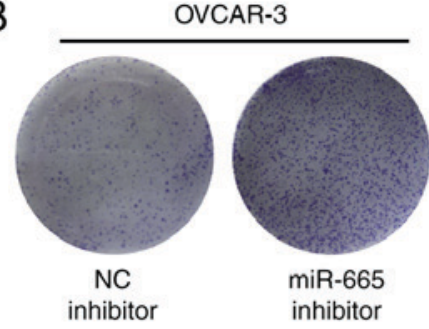

D

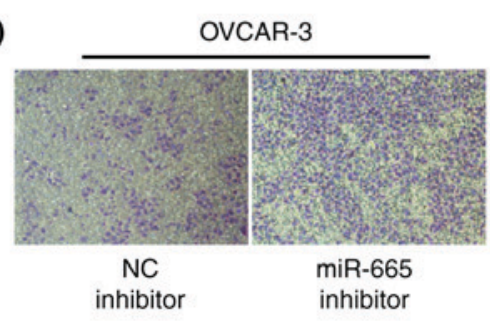

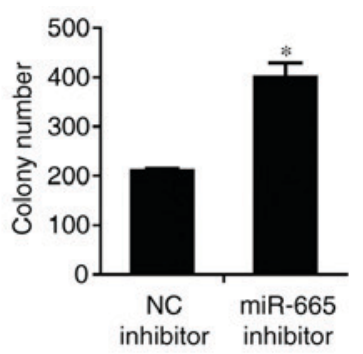

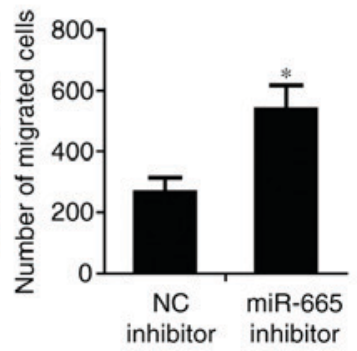

Figure 6. miR-665 inhibitor promotes cell proliferation and migration of ovarian cancer cells. Effect of miR-665 on cell proliferation was evaluated by a colony formation assay. (A) HO8910 and (B) OVCAR-3 cells transfected with miR-665 inhibitor or NC inhibitor were seeded into 6-well plates. On day 10 after seeding, the number of colonies was counted. "P<0.05 (C) HO8910 and (D) OVCAR-3 cells were transfected with miR-665 inhibitor or NC inhibitor for 48 h. Transwell chambers were used for cell migration assays. Magnification, x100. ${ }^{*} \mathrm{P}<0.05$ vs. NC. miR, microRNA; NC, negative control.

and 81272871) and the Postgraduate Research \& Practice Innovation Program of Jiangsu Province (grant no. JX22013366)

\section{Availability of data and materials}

Not applicable.

\section{Authors' contributions}

Conceived and designed the experiments: WJC. Performed the experiments: JHL, YJ. Analyzed the data and wrote the manuscript: JHL, YJ, YCW. Performed part of the experiments and bioinformatics analyses: SLZ, ST. All authors read and approved the final manuscript. 


\section{Ethics approval and consent to participate}

The study was approved by the Ethics Committee of the Nanjing Medical University and samples were obtained with informed consent from all patients.

\section{Patient consent for publication}

Informed consent was obtained from all patients.

\section{Competing interests}

The authors declare that they have no competing interests.

\section{References}

1. Xian H, Xian Y, Liu L, Wang Y, He J and Huang J: Expression of $\beta$-nerve growth factor and homeobox A10 in experimental cryptorchidism treated with exogenous nerve growth factor. Mol Med Rep 11: 2875-2881, 2015.

2. Guo R, Sherman-Baust C and Abdelmohsen K: miRNA-based ovarian cancer diagnosis and therapy. In: Sarkar F (ed) MicroRNA Targeted Cancer Therapy. Springer, Cham, pp115-127, 2014.

3. Bartel DP: MicroRNAs: Genomics, biogenesis, mechanism, and function. Cell 116: 281-297, 2004.

4. Hornstein E, Mansfield JH, Yekta S, Hu JK, Harfe BD, McManus MT, Baskerville S, Bartel DP and Tabin CJ: The microRNA miR-196 acts upstream of Hoxb8 and Shh in limb development. Nature 438: 671-674, 2005.

5. Boehm M and Slack FJ: microRNA control of lifespan and metabolism. Cell Cycle 5: 837-840, 2006.

6. Tang W, Jiang Y, Mu X, Xu L, Cheng W and Wang X: MiR-135a functions as a tumor suppressor in epithelial ovarian cancer and regulates HOXA10 expression. Cell Signal 26: 1420-1426, 2014.

7. Wang F, Chang TH, Kao CJ and Huang RS: High expression of miR-532-5p, a tumor suppressor, leads to better prognosis in ovarian cancer both in vivo and in vitro. Mol Cancer Ther 15: 1123-1131, 2016

8. Zhao H, Yu X, Ding Y, Zhao J, Wang G, Wu X, Jiang J, Peng C, Guo GZ and Cui S: MiR-770-5p inhibits cisplatin chemoresistance in human ovarian cancer by targeting ERCC2. Oncotarget 7: 53254-53268, 2016

9. Zhao X, Zhou Y, Chen YU and Yu F: miR-494 inhibits ovarian cancer cell proliferation and promotes apoptosis by targeting FGFR2. Oncol Lett 11: 4245-4251, 2016.

10. $\mathrm{Hu} \mathrm{K}$ and Liang M: Upregulated microRNA-224 promotes ovarian cancer cell proliferation by targeting KLLN. In Vitro Cell Dev Biol Anim 53: 149-156, 2017.

11. Xiaohong Z, Lichun F, Na X, Kejian Z, Xiaolan X and Shaosheng W: MiR-203 promotes the growth and migration of ovarian cancer cells by enhancing glycolytic pathway. Tumour Biol 37: 14989-14997, 2016

12. Chen S, Chen X, Xiu YL, Sun KX and Zhao Y: MicroRNA-490-3P targets CDK1 and inhibits ovarian epithelial carcinoma tumorigenesis and progression. Cancer Lett 362: 122-130, 2015.

13. Zheng HB, Zheng XG and Liu BP: miRNA-101 inhibits ovarian cancer cells proliferation and invasion by down-regulating expression of SOCS-2. Int J Clin Exp Med 8: 20263-20270, 2015.

14. Zang W, Wang Y, Du Y, Xuan X, Wang T, Li M, Ma Y, Li P, Chen X, Dong Z and Zhao G: Differential expression profiling of microRNAs and their potential involvement in esophageal squamous cell carcinoma. Tumor Biol 35: 3295-3304, 2014.

15. Cheng W, Gao JP, Zhang ZG, Jing-Ping GE, Feng XU and Wei ZF: Study on microRNAs in urothelial carcinoma(II grade) of the bladder. J Med Postgrad 23: 48-52, 2010.

16. Chen J, Sun D, Chu H, Gong Z, Zhang C, Gong B, Li Y, Li N and Jiang L: Screening of differential microRNA expression in gastric signet ring cell carcinoma and gastric adenocarcinoma and target gene prediction. Oncol Rep 33: 2963-2971, 2015.

17. Hatanaka Y, De Velasco MA, Kura Y, Yamamoto Y, Kodama M, Nozawa M, Shimizu N, Yoshimura K, Yoshikawa K, Nishio K and Uemura H: Abstract 3629: HOXA10 expression profiles in prostate cancer. Cancer Res 72 (8 Suppl): S3629, 2012.

18. Thorsteinsdottir U, Sauvageau G, Hough MR, Dragowska W, Lansdorp PM, Lawrence HJ, Largman C and Humphries RK: Overexpression of HOXA10 in murine hematopoietic cells perturbs both myeloid and lymphoid differentiation and leads to acute myeloid leukemia. Mol Cell Biol 17: 495-505, 1997.
19. Chu MC, Selam FB and Taylor HS: HOXA10 regulates p53 expression and matrigel invasion in human breast cancer cells. Cancer Biol Ther 3: 568-572, 2004.

20. Chen Y, Zhang J, Wang H, Zhao J, Xu C, Du Y, Luo X, Zheng F, Liu R, Zhang H and Ma D: miRNA-135a promotes breast cancer cell migration and invasion by targeting HOXA10. BMC Cancer 12: 111, 2012.

21. Carrera M, Bitu CC, de Oliveira CE, Cervigne NK, Graner E, Manninen A, Salo T and Coletta RD: HOXA10 controls proliferation, migration and invasion in oral squamous cell carcinoma. Int J Clin Exp Pathol 8: 3613-3623, 2015.

22. Kim JW, Kim JY, Kim JE, Kim SK, Chung HT and Park CK: HOXA10 is associated with temozolomide resistance through regulation of the homologous recombinant DNA repair pathway in glioblastoma cell lines. Genes Cancer 5: 165-174, 2014.

23. Zhang L, Wan Y, Jiang Y, Ma J, Liu J, Tang W, Wang X and Cheng W: Upregulation HOXA10 homeobox gene in endometrial cancer: Role in cell cycle regulation. Med Oncol 31: 52, 2014.

24. Livak KJ and Schmittgen TD: Analysis of relative gene expression data using real-time quantitative PCR and the 2(-Delta Delta C(T)) method. Methods 25: 402-408, 2001.

25. Jougla E: Survival of cancer patients in Europe (EUROCARE study). Rev Epidemiol Sante Publique 44: 473-475, 1996 (In French).

26. Coward JI, Middleton K and Murphy F: New perspectives on targeted therapy in ovarian cancer. Int J Womens Health 7: 189-203, 2015

27. Zaman MS, Maher DM, Khan S, Jaggi M and Chauhan SC: Current status and implications of microRNAs in ovarian cancer diagnosis and therapy. J Ovarian Res 5: 44, 2012.

28. Nikitina EG, Urazova LN and Stegny VN: MicroRNAs and human cancer. Exp Oncol 34: 2-8, 2012.

29. Kim TH, Song JY, Park H, Jeong JY, Kwon AY, Heo JH, Kang H, Kim G and An HJ: miR-145, targeting high-mobility group A2, is a powerful predictor of patient outcome in ovarian carcinoma. Cancer Lett 356: 937-945, 2015.

30. Xu S, Fu GB, Tao Z, OuYang J, Kong F, Jiang BH, Wan X and Chen K: MiR-497 decreases cisplatin resistance in ovarian cancer cells by targeting mTOR/P70S6K1. Oncotarget 6: 26457-26471, 2015.

31. Guan Y, Yao H, Zheng Z, Qiu G and Sun K: MiR-125b targets BCL 3 and suppresses ovarian cancer proliferation. Int J Cancer 128: 2274-2283, 2011

32. Lee YS and Dutta A: MicroRNAs in cancer. Annu Rev Pathol 4: 199-227, 2009

33. Nygren MK, Tekle C, Ingebrigtsen VA, Mäkelä R, Krohn M, Aure MR, Nunes-Xavier CE, Perälä M, Tramm T, Alsner J, et al: Identifying microRNAs regulating B7-H3 in breast cancer: The clinical impact of microRNA-29c. Br J Cancer 110: 2072-2080, 2014.

34. Kim JJ, Taylor HS, Lu Z, Ladhani O, Hastings JM, Jackson KS Wu Y, Guo SW and Fazleabas AT: Altered expression of HOXA10 in endometriosis: Potential role in decidualization. Mol Hum Reprod 13: 323-332, 2007.

35. Kelly M, Daftary G and Taylor HS: An autoregulatory element maintains HOXA10 expression in endometrial epithelial cells. Am J Obstet Gynecol 194: 1100-1109, 2006.

36. Daftary GS, Troy PJ, Bagot CN, Young SL and Taylor HS: Direct regulation of beta3-integrin subunit gene expression by HOXA10 in endometrial cells. Mol Endocrinol 16: 571-579, 2002.

37. Cheng W, Liu J, Yoshida H, Rosen D and Naora H: Lineage infidelity of epithelial ovarian cancers is controlled by HOX genes that specify regional identity in the reproductive tract. Nat Med 11: 531-537, 2005.

38. Shih IeM, Chen L, Wang CC, Gu J, Davidson B, Cope L, Kurman RJ, Xuan J and Wang TL: Distinct DNA methylation profiles in ovarian serous neoplasms and their implications in ovarian carcinogenesis. Am J Obstet Gynecol 203: 584.e1-22, 2010.

39. Pan BL, Tong ZW, Wu L, Pan L, Li JE, Huang YG, Li SD, Du SX and Li XD: Effects of MicroRNA-206 on osteosarcoma cell proliferation, apoptosis, migration and invasion by targeting ANXA2 through the AKT signaling pathway. Cell Physiol Biochem 45: 1410-1422, 2018.

40. Libório-Kimura TN, Jung HM and Chan EK: miR-494 represses HOXA10 expression and inhibits cell proliferation in oral cancer. Oral Oncol 51: 151-157, 2015.

41. Li B, Jin H, Yu Y, Gu C, Zhou X, Zhao N and Feng Y: HOXA10 is overexpressed in human ovarian clear cell adenocarcinoma and correlates with poor survival. Int J Gynecol Cancer 19: $1347-1352,2009$.

This work is licensed under a Creative Commons Attribution-NonCommercial-NoDerivatives 4.0 International (CC BY-NC-ND 4.0) License. 